\title{
Tobacco Use Among Students Aged 13-15 Years in South Korea: The 2013 Global Youth Tobacco Survey
}

\author{
Sunhye Choi', Yoonjung Kim', Jihye Lee', Mina Kashiwabara², Kyungwon Oh' \\ ${ }^{1}$ Division of Health and Nutrition Survey, Centers for Disease Control and Prevention, Cheongju, Korea; ${ }^{2}$ Tobacco Free Initiative, World Health \\ Organization Regional Office for the Western Pacific, Manila, Philippines
}

Objectives: We examined the prevalence of tobacco use and exposure to secondhand smoke among middle-school students in Korea using the Global Youth Tobacco Survey (GYTS) in 2013.

Methods: The GYTS in Korea was conducted between July and August 2013 by the Korea Centers for Disease Control and Prevention. Data were collected using a self-administered anonymous questionnaire from a nationally representative sample of middle-school students aged 13-15 years in sampled classrooms.

Results: The GYTS in Korea was completed by 4235 students aged 13-15 years in 43 middle schools. Approximately one in five of the students (17.8\%) reported that they had tried cigarettes in the past, while 5.2\% reported currently being cigarette smokers. Current cigarette smoking was higher in boys (7.5\%) than in girls (2.6\%). Of the students, $29.7 \%$ had been exposed to secondhand smoke at home, $47.4 \%$ inside enclosed public places, and $53.9 \%$ in outdoor public places. Of the current cigarette smokers, $25.7 \%$ bought their cigarettes from a store despite a law prohibiting this. Additionally, 58.0\% of students noticed point-of-sale tobacco advertisements or promotions, $66.8 \%$ of current cigarette smokers wanted to stop smoking, and $70.9 \%$ of students had been taught about the dangers of tobacco use in school.

Conclusions: These findings provide an opportunity to develop, implement, and evaluate a comprehensive tobacco control policy. The results suggest that youth have relatively easy access to cigarettes and are regularly exposed to secondhand smoke in public places, as well as to point-of-sale tobacco advertisements and promotions. Strict enforcement of the ban on tobacco sales to youth, expanding smoke-free areas, and advertising bans are needed to reduce tobacco use among youth.

Key words: Global Youth Tobacco Survey, Republic of Korea, Tobacco use

Received: August 24, 2016, Accepted: December 29, 2016

Corresponding author: Kyungwon Oh, $\mathrm{PhD}$

187 Osongsaengmyeong 2-ro, Heungdeok-gu, Cheongju 28159, Korea

Tel: +82-43-719-7460, Fax: +82-43-719-7527

E-mail: kwoh27@korea.kr

This is an Open Access article distributed under the terms of the Creative Commons Attribution Non-Commercial License (http://creativecommons.org/licenses/by$\mathrm{nc} / 4.0 /$ ) which permits unrestricted non-commercial use, distribution, and reproduction in any medium, provided the original work is properly cited.

\section{INTRODUCTION}

Tobacco use is a major preventable risk factor for premature death and disease worldwide [1]. The World Health Organization (WHO) attributes approximately six million deaths per year to tobacco use, a number that is expected to exceed eight million per year by 2030 [2]. The United Nations has acknowledged the importance of reducing the prevalence of tobacco use in order to prevent and control non-communicable diseases through the implementation of multi-sectoral action plans [3]. To facilitate the implementation of the demand re- 
duction policies of the Framework Convention on Tobacco Control (FCTC), the WHO has advised a set of policies known as MPOWER: Monitor tobacco use and prevention policies, Protect people from tobacco smoke, Offer help to quit tobacco use, Warn about the dangers of tobacco, Enforce bans on tobacco advertising and sponsorship, and Raise taxes on tobacco. Korea ratified the FCTC in 2005 and subsequently amended the National Health Promotion Act accordingly. The Korean government imposed additional charges on electronic cigarettes in 2011, restricted advertisements and imposed a ban on the display of flavor compounds in 2012, designated all enclosed public areas smoke-free and raised the cigarette price by $80 \%$ in 2015 , and began enforcing image-based cigarette package warnings in 2016. Monitoring of tobacco use is a fundamental part of tobacco control, as data collected through surveys aid in understanding the current state of the epidemic, as well as the impact of tobacco control policies and industry tactics. Monitoring tobacco use among youth is especially important, as youth is a critical period for tobacco control. Evidence indicates that if young people can remain free of tobacco until age 18, most will never start to smoke [4], and among adults who smoke daily, nearly all started smoking cigarettes before 18 years of age [5].

The Global Youth Tobacco Survey (GYTS) is a joint project of the WHO and the US Centers for Diseases Control and Prevention (CDC) aiming to obtain comparable behavioral data from different countries on the prevalence of cigarette and other tobacco use; perceptions and attitudes about tobacco; access and availability of tobacco products; exposure to secondhand smoke, media, and advertising, and smoking cessation interventions through a standardized school-based survey $[6,7]$. Although the method is standardized across countries, each country is permitted to adapt the questionnaire in order to collect data on issues that are particularly important in the local context. South Korea (hereafter Korea) has participated in the GYTS three times (in 2005, 2008, and 2013).

The purpose of this paper was to present the prevalence of smoking, secondhand smoke exposure, and susceptibility to smoking among middle-school students based on the findings of the GYTS conducted in Korea in 2013.

\section{METHODS}

The GYTS uses a standardized methodology for constructing sampling frames, selecting schools and classes, preparing questionnaires, conducting field procedures, and processing data.

\section{Sample Design}

The GYTS standard sampling methodology uses a two-stage cluster sample design that generates samples of students in grades attended by students aged 13-15 years. In the GYTS in Korea in 2013, all public and private schools across 16 provinces that contained 50 or more enrolled students in grades 7-9 were included in the sampling frame. In the first stage, the probability of schools being selected was proportional to the number of students enrolled in the specified grades. In the second sampling stage, classes within grades 7-9 in the selected schools were randomly selected. All enrolled students in the selected classes the day the survey was administered were eligible to participate. Student participation was voluntary and anonymous, and self-administered data collection procedures were used.

\section{Questionnaire}

The GYTS questionnaire used in Korea included a total of 53 questions, consisting of 43 core questions and 10 optional questions covering tobacco use (smoking and smokeless), cessation, exposure to secondhand smoking, pro-tobacco and anti-tobacco media and advertising, access and ability to obtain tobacco products, and knowledge and attitudes about tobacco. The questionnaires were translated into Korean and back-translated into English to check the accuracy of the translation. Prior to the full survey, focus groups of students aged 13-15 years were conducted to further test the accuracy and comprehension of the questions.

\section{Data Collection}

GYTS data collection was led by the Korea Centers for Disease Control and Prevention (KCDC), with the cooperation of the Ministry of Education and the Metropolitan and Provincial Offices of Education. The questionnaires were distributed to each class of the selected schools by teachers who were trained as field workers by the KCDC.

\section{Statistical Analyses}

A weighting factor was applied to each student record to adjust for non-response (by school, class, and student) and variation in the probability of selection at the school, class, and student levels. Respondents' grade and sex were also tak- 
en into account.

Analyses were performed using SAS version 9.4 (SAS Institute Inc., Cary, NC, USA), a software package for the statistical analysis of correlated data, in order to calculate weighted prevalence estimates and $95 \%$ confidence interval $(\mathrm{Cl})$. Differences in proportions were evaluated using $95 \%$ Cls. Additionally, we considered the sampling design in our analysis when estimating the prevalence of various outcomes.

\section{RESULTS}

In 2013, the survey was completed by 4235 of the 4349 sampled students from the 43 sampled middle schools. The overall response rate was $97.4 \%$, calculated as the product of the school response rate $(100.0 \%)$, the class response rate (100.0\%), and the student response rate (97.4\%).

\section{Tobacco Use}

A total of $17.8 \%$ (boys, $25.1 \%$; girls, 9.9\%) of 13-15-year-old students in Korea had ever smoked cigarettes (Table 1). Of the students, 5.2\% had smoked cigarettes at any time during the past 30 days, with more boys (7.5\%) than girls (2.6\%) reporting this to be the case. The prevalence of ever using tobacco products other than cigarettes (e.g., pipes, cigars, mini cigars/ cigarillos, water pipes/hookahs, or bidis) was 3.8\% (boys, 4.9\%; girls, 2.5\%) and the prevalence of ever using smokeless tobacco (e.g., snuff, chewing tobacco, dip, betel quid with tobacco, or gutka) was $2.0 \%$ (boys, $2.4 \%$; girls, $1.5 \%$ ). Of those who had ever smoked cigarettes, $8.3 \%$ initiated smoking before the age of 10 , and $12.3 \%$ of those who had never used tobacco reported being susceptible to using tobacco in the future.

\section{Exposure to Smoke}

One in two students (50.5\%) had at least one parent who smoked, and two in five students (39.8\%) reported that their closest friends smoked (Table 2). One in three students (29.7\%) had been exposed to secondhand smoke at home in the past seven days. Exposure to secondhand smoke inside any enclosed public places (e.g., school store, restaurant, shopping mall, theatre, PC room, or karaoke lounge) was reported by $47.4 \%$ of students (boys, $52.1 \%$; girls, $42.0 \%$ ) and exposure in any outdoor public places (e.g., school yard, street, building entrance, park, beach, playground, or bus station) was reported by $53.9 \%$ of respondents (boys, $44.9 \%$; girls, $63.5 \%$ ). Approximately two in five students (43.9\%) reported having seen someone smoke inside the school building or outside on school property. Overall, nine in 10 students were in favor of banning smoking in public places, with $91.2 \%$ in favor of banning smoking in enclosed spaces and $90.0 \%$ in favor of banning smoking in outdoor spaces.

Table 1. Prevalence of tobacco use among students aged 13-15 years by sex, Korea, 2013

\begin{tabular}{|c|c|c|c|}
\hline Characteristic & Total & Boys & Girls \\
\hline \multicolumn{4}{|l|}{ Smoked tobacco use } \\
\hline Ever cigarette smokers ${ }^{1}$ & $17.8(15.1,20.9)$ & $25.1(21.2,29.4)$ & $9.9(7.8,12.4)$ \\
\hline Ever smokers of other tobacco products ${ }^{3}$ & $3.8(2.9,4.9)$ & $4.9(3.7,6.4)$ & $2.5(1.6,3.9)$ \\
\hline Current smokers of other tobacco products ${ }^{4}$ & $1.3(0.8,2.1)$ & $1.8(1.1,2.8)$ & $0.7(0.3,2.0)$ \\
\hline Ever smokeless tobacco users ${ }^{6}$ & $2.0(1.3,2.9)$ & $2.4(1.6,3.6)$ & $1.5(0.9,2.6)$ \\
\hline Current smokeless tobacco users $^{7}$ & $0.9(0.4,1.9)$ & $0.9(0.4,2.0)$ & $0.9(0.4,2.0)$ \\
\hline \multicolumn{4}{|l|}{ Susceptibility } \\
\hline Never tobacco users susceptible to tobacco use ${ }^{8}$ & $12.3(10.8,14.1)$ & $13.1(11.0,15.7)$ & $11.6(9.6,14.0)$ \\
\hline
\end{tabular}

Source from Global Youth Tobacco Survey, 2013.

Values are presented as \% (95 confidence interval).

1Percentage of youth who reported ever having smoked cigarettes.

2Percentage of youth who reported currently smoking cigarettes.

${ }^{3}$ Percentage of youth who reported ever having smoked tobacco products other than cigarettes.

${ }^{4}$ Percentage of youth who reported currently smoking tobacco products other than cigarettes.

${ }^{5}$ Percentage of ever cigarette smokers who first smoked cigarettes before the age of 10 years.

${ }^{6}$ Percentage of youth who reported ever having used any smokeless tobacco products.

${ }^{7}$ Percentage of youth who reported currently using smokeless tobacco products.

${ }^{8}$ Percentage of never tobacco users who reported being susceptible to using tobacco in the future. 


\section{Media and Advertising Exposure}

Seven in 10 students (71.4\%) reported having seen an antitobacco media message on television, radio, Internet, billboards, posters, newspapers, magazines, or movies during the past 30 days (Table 2). However, almost three in five students (58.0\%) reported being exposed to pro-tobacco advertise- ments or promotions at points of sale (e.g., stores, markets, or kiosks). Of the students, $2.6 \%$ had an object with a tobacco product brand logo on it (e.g., t-shirt, pen, or backpack), and $1.8 \%$ of students had ever been offered a free tobacco product from a tobacco company representative.

Table 2. Prevalence of factors influencing tobacco use among students aged 13-15 years by sex, Korea, 2013

\begin{tabular}{|c|c|c|c|}
\hline Indicators & Total & Boys & Girls \\
\hline \multicolumn{4}{|l|}{ Exposure to smoke } \\
\hline One or more parents smoke ${ }^{1}$ & $50.5(47.7,53.4)$ & $50.4(47.3,53.6)$ & $50.5(47.1,54.0$ \\
\hline Best friend smokes ${ }^{2}$ & $39.8(35.1,44.4)$ & $51.3(45.5,57.1)$ & $27.1(23.8,30.4$ \\
\hline Exposed to tobacco smoke at home ${ }^{3}$ & $29.7(28.3,31.0)$ & $27.3(25.2,29.6)$ & $32.0(29.7,34.3$ \\
\hline Exposed to tobacco smoke inside any enclosed public places ${ }^{4}$ & $47.4(44.1,50.6)$ & $52.1(48.0,56.2)$ & $42.0(39.0,45.1$ \\
\hline Exposed to smoke at any outdoor public places ${ }^{5}$ & $53.9(50.9,56.8)$ & $44.9(42.0,47.8)$ & $63.5(59.8,67.1$ \\
\hline Witnessed smoking inside the school building or outside on school property ${ }^{6}$ & $43.9(39.6,48.3)$ & $44.6(39.1,50.3)$ & $43.0(38.7,47.4$ \\
\hline \multicolumn{4}{|l|}{ Knowledge and attitudes } \\
\hline Favored banning smoking inside enclosed public places ${ }^{7}$ & $91.2(90.0,92.3)$ & $91.1(89.4,92.6)$ & $91.3(89.5,92.8$ \\
\hline Favored banning smoking at outdoor public places ${ }^{8}$ & $90.0(88.6,91.2)$ & $89.5(87.5,91.3)$ & $90.4(88.9,91.7$ \\
\hline \multicolumn{4}{|l|}{ Media/advertising } \\
\hline Anti-tobacco messages in the media ${ }^{9}$ & $71.4(69.0,73.6)$ & $72.9(69.8,75.8)$ & $69.7(66.4,72.8$ \\
\hline Pro-tobacco messages in stores ${ }^{10}$ & $58.0(56.0,60.0)$ & $60.6(57.5,63.8)$ & $55.2(52.5,57.9$ \\
\hline Owned something with a tobacco brand logo on it ${ }^{11}$ & $2.6(2.0,3.3)$ & $2.8(1.8,4.2)$ & $2.3(1.7,3.1)$ \\
\hline Ever offered a free tobacco product from a tobacco company ${ }^{12}$ & $1.8(1.4,2.2)$ & $1.9(1.4,2.7)$ & $1.7(1.1,2.5)$ \\
\hline \multicolumn{4}{|l|}{ Cessation } \\
\hline Want to stop smoking now ${ }^{13}$ & $66.8(55.1,76.8)$ & $73.7(61.4,83.1)$ & $N A^{18}$ \\
\hline Tried to stop smoking in the past 12 months ${ }^{14}$ & $78.4(71.4,84.1)$ & $81.2(71.1,88.3)$ & $71.0(53.0,84.2$ \\
\hline \multicolumn{4}{|l|}{ Access } \\
\hline Buy cigarettes from a store ${ }^{15}$ & $25.7(17.2,36.5)$ & $28.5(18.4,41.3)$ & $18.3(8.8,34.1)$ \\
\hline Not prevented from buying cigarettes because of their age $\mathrm{e}^{16}$ & $29.2(19.8,40.8)$ & $28.6(17.3,43.4)$ & $N A^{18}$ \\
\hline \multicolumn{4}{|l|}{ School curricula } \\
\hline Taught in school about the danger of tobacco use $\mathrm{s}^{17}$ & $70.9(65.2,76.1)$ & $74.2(68.5,79.2)$ & $67.6(59.1,75.0$ \\
\hline
\end{tabular}

Source from Global Youth Tobacco Survey, 2013.

Values are presented as \% (95\% confidence interval).

'Percentage of youth who reported having been exposed to tobacco smoke from their parents.

${ }^{2}$ Percentage of youth who reported having been exposed to tobacco smoke from their best friends.

${ }^{3}$ Percentage of youth who reported having been exposed to tobacco smoke at home during the past 7 days.

${ }^{4}$ Percentage of youth who reported having been exposed to tobacco smoke in enclosed public places during the past 7 days.

${ }^{5}$ Percentage of youth who reported having been exposed to tobacco smoke at outdoor public places during the past 7 days.

${ }^{6}$ Percentage of youth who reported having seen anyone smoke inside the school building or outside on school property during the past 30 days.

${ }^{7}$ Percentage of youth who were in favor of banning smoking in enclosed public places.

${ }^{8}$ Percentage of youth who were in favor of banning smoking at outdoor public places.

${ }^{9}$ Percentage of youth who reported having seen or heard any anti-tobacco messages in the media (on television, radio, internet, billboards, posters, newspapers, magazines, or movies) during the past 30 days.

${ }^{10}$ Percentage of youth who reported having seen any tobacco marketing at points of sale (such as stores and shops) during the past 30 days.

${ }^{11}$ Percentage of youth who owned something with a tobacco product brand logo on it.

${ }^{12}$ Percentage of youth who reported ever having been offered a free tobacco product from a tobacco company representative.

${ }^{13}$ Percentage of current smokers who wanted to stop smoking.

${ }^{14}$ Percentage of current smokers who reported that they had tried to stop smoking during the past 12 months.

${ }^{15}$ Percentage of current cigarette smokers who last obtained cigarettes from stores or markets during the past 30 days.

${ }^{16}$ Percentage of current cigarette smokers who had not been prevented from buying cigarettes during the past 30 days because of their age.

${ }^{17}$ Percentage of youth who were taught about the dangers of tobacco use in class during the past 12 months.

${ }^{18}$ Fewer than 35 respondents. 


\section{Media and Advertising Exposure}

Seven in 10 students (71.4\%) reported having seen an antitobacco media message on television, radio, Internet, billboards, posters, newspapers, magazines, or movies during the past 30 days (Table 2). However, almost three in five students (58.0\%) reported being exposed to pro-tobacco advertisements or promotions at points of sale (e.g., stores, markets, or kiosks). Of the students, $2.6 \%$ had an object with a tobacco product brand logo on it (e.g., t-shirt, pen, or backpack), and $1.8 \%$ of students had ever been offered a free tobacco product from a tobacco company representative.

\section{Access}

One in four current cigarette smokers (25.7\%) usually purchased their cigarettes in a store or market (Table 2). Almost one in three (29.2\%) current cigarette smokers had not been prevented from purchasing cigarettes because of their age.

\section{Cessation}

Almost seven in 10 (66.8\%) current cigarette smokers reported that they desired to stop smoking (Table 2). Additionally, almost four in five current cigarette smokers (78.4\%) had tried to stop smoking during the past year. Seven in 10 students (70.9\%) reported having been taught in school about the dangers of smoking during the past year

\section{DISCUSSION}

This study was an international evaluation of tobacco use carried out among middle-school students in Korea. The prevalence of current cigarette smokers in this age group in Korea was $5.2 \%$ in 2013, and almost one in two students were exposed to secondhand smoking in public places (enclosed or outdoor), although Korea has a policy of smoke-free public areas. Despite extensive marketing by the tobacco industry, approximately seven in 10 students who currently smoked reported that they wanted to stop smoking. Although Korea has a law banning the sale of tobacco products to adolescents, approximately one in four students who smoked had not been prevented from purchasing tobacco from stores.

Before the 2013 GYTS, Korea had conducted the GYTS in 2005 and 2008. In 2005 and 2008, 6.8\% and 8.8\% of students, respectively, had smoked cigarettes at any time during the past 30 days, which are higher than the value of $5.2 \%$ reported in 2013 [8]. The prevalence in Korea was lower than the medi- an of 6.8\% reported in 45 countries in 2013-2014 (range, 1.7\% [Kazakhstan] to $28.9 \%$ [Timor-Leste]) [9]. The prevalence of usually buying cigarettes in a store among middle-school students in Korea was found to be higher than has been reported in the US $(2004,7.7 \%)$ and New Zealand $(2007,12.6 \%)$ which have laws banning the sale of tobacco products to minors [6].

Korea has also conducted a national school-based crosssectional survey since 2005. The Korea Youth Risk Behavior Web-based Survey (KYRBS) is conducted annually to monitor health-risk behavior among Korean adolescents [10]. According to this survey in 2013, $14.7 \%$ (boys, 20.5\%; girls, 8.4\%) of 13-15-year-old students had ever smoked, while $5.5 \%$ reported being current cigarette smokers, with more current cigarette smokers among boys (7.9\%) than girls (2.8\%). Of the students, $31.4 \%$ were exposed to tobacco smoke at home and $70.2 \%$ of smokers had tried to stop smoking in the past 12 months [11]. These results are similar to those of the GYTS.

A number of limitations of this report must be acknowledged. First, because the survey was limited to students, it is not representative of all youths aged 13-15 years in Korea. However, based on our calculations using data from the Ministry of Education and Statistics Korea, only approximately 5.1\% of persons aged 13-15 years were not enrolled in school. Second, the data collected were based on self-reporting by students, who may have under-reported or over-reported their answers. The extent of this bias cannot be determined; however, a study of the validity of the KYRBS in Korea found good validity for similar tobacco-related questions using urine cotinine levels for verification [12].

In summary, we confirmed the prevalence of smoking in Korea among students aged 13-15 years, and found that these students used other tobacco products as well as cigarettes. Moreover, youth reported having relatively easy access to cigarettes, as well as being regularly exposed to secondhand smoke in public places and to point-of-sale tobacco advertisements and promotions. It is suggested that the strict enforcement of the ban on tobacco sales to youth, expanding smokefree areas, and advertising bans are needed to reduce tobacco use among youth.

Korea must continuously monitor the prevalence of smoking among youth in order to reduce tobacco use and to establish more positive policies to prevent students under the age of 18 from starting smoking and to protect them from the risk of secondhand smoking, in accordance with the MPOWER policies. 


\section{ACKNOWLEDGEMENTS}

We would like to acknowledge the technical support provided by the GYTS team at the US Centers for Disease Control and Prevention for the implementation and analysis of the GYTS in South Korea.

\section{CONFLICT OF INTEREST}

The authors have no conflicts of interest associated with the material presented in this paper.

\section{ORCID}

Sunhye Choi https://orcid.org/0000-0002-2942-0290

Kyungwon Oh https://orcid.org/0000-0001-8097-6078

\section{REFERENCES}

1. Jha P, Chaloupka FJ. Tobacco control in developing countries. Oxford; Oxford University Press; 2000, p. 11-40.

2. World Health Organization. WHO report on the global epidemic, 2008: the MPOWER package [cited 2017 Jan 7]. Available from: http://apps.who.int/iris/bitstream/10665/43818/ 1/9789241596282_eng.pdf.

3. World Health Organization. Political declaration of the highlevel meeting of the general assembly on the prevention and control of non-communicable diseases; 2012 [cited 2017 Jan 7]. Available from: http://www.who.int/nmh/events/un_ncd_ summit2011/political_declaration_en.pdf.

4. US Department of Health and Human Services. Preventing tobacco use among young people: a report of the Surgeon General; 1994 [cited 2017 Jan 7]. Available from: https://www. cdc.gov/mmwr/pdf/rr/rr4304.pdf.

5. US Department of Health and Human Services. Preventing tobacco use among youth and young adults: a report of the Surgeon General; 2012 [cited 2017 Jan 7]. Available from: https://www.surgeongeneral.gov/library/reports/preventingyouth-tobacco-use/full-report.pdf.

6. Warren CW, Jones NR, Peruga A, Chauvin J, Baptiste JP, Costa de Silva V, et al. Global youth tobacco surveillance, 2000-2007. MMWR Surveill Summ 2008;57(1):1-28.

7. Global Youth Tobacco Survey Collaborating Group. Differences in worldwide tobacco use by gender: findings from the Global Youth Tobacco Survey. J Sch Health 2003;73(6):207-215.

8. Centers for Disease Control and Prevention. Global tobacco surveillance system data (GTSSData) [cited 2017 Jan 7]. Available from: https://www.cdc.gov/tobacco/global/gtss/gtssdata/index.html.

9. D’Angelo D, Ahluwalia IB, Pun E, Yin S, Palipudi K, Mbulo L. Current cigarette smoking, access, and purchases from retail outlets among students aged 13-15 years - Global Youth Tobacco Survey, 45 countries, 2013 and 2014. MMWR Morb Mortal Wkly Rep 2016;65(34):898-901.

10. Kim Y, Choi S, Chun C, Park S, Khang YH, Oh K. Data resource profile: the Korea Youth Risk Behavior Web-based Survey (KYRBS). Int J Epidemiol 2016;45(4):1076-1076e.

11. Ministry of Health and Welfare; Centers for Disease Control and Prevention; Ministry of Education. Korea youth health statistics; 2013 [cited 2017 Jan 18]. Available from: https://yhs. cdc.go.kr/new/pages/pds1.asp (Korean).

12. Korea Centers for Disease Control and Prevention. Reliability and validity of the Korea Youth Risk Behavior Web-based Survey questionnaire; 2009 [cited 2017 Jan 18]. Available from: https://yhs.cdc.go.kr/new/pages/pds3.asp (Korean). 